\title{
Profissionais de saúde de um serviço de emergência hospitalar: discursividades em torno do cuidado
}

| ${ }^{1}$ Sander Machado Silva, ${ }^{2}$ Márcia Ziebell Ramos |

Resumo: O estudo objetiva investigar as discursividades dos profissionais de saúde de um serviço de emergência hospitalar em torno do cuidado e suas possíveis implicaçôes para assistência à saúde. A pesquisa possui caráter qualitativo $\mathrm{e}$ os arquivos discursivos foram coletados através de entrevistas semiestruturadas com os referidos profissionais. Utiliza-se, na análise de tais arquivos, o método genealógico de Foucault e estabelece-se uma discussão interdisciplinar, constituindo-se como uma leitura crítica em resposta ao problema de pesquisa. Nesse sentido, destaca-se sua implicação ético-política frente à realidade atual do campo da saúde. $\mathrm{Na}$ discussão realizada, problematizam-se o conceito de saúde e suas relações com a noção de cuidado, situando, nesse contexto, os discursos dos participantes sobre sua experiência cotidiana e questionando os jogos de verdade observados. Conclui-se, a partir da reflexão realizada pelo estudo, a emergência de se rediscutir e remanejar, no cenário em pauta, os processos de comunicação e o conceito de interdisciplinaridade. Propõe-se, com isso, uma oxigenação das práticas de cuidado e a efetiva humanização dos processos envolvidos. hospitalar; interdisciplinaridade; comunicação.

\footnotetext{
1 Centro de Estudos

Psicanalíticos de Porto Alegre (CEPdePA), Porto Alegre-RS,

Brasil. Endereço eletrônico:

sander.machado@gmail.com

${ }^{2}$ Hospital de Clínicas de Porto Alegre (HCPA), Porto Alegre,-RS Brasil. Endereço eletrônico: mramos@hcpa.ufrgs.br
} 


\section{Saúde e cuidado: introduzindo uma genealogia}

O cenário acadêmico da atualidade coloca em evidência uma polissemia em torno do conceito de saúde - ou seja, no que se refere ao conceito em pauta, mas também e necessariamente aos processos e dispositivos associados. Não obstante, a noção de saúde proposta pela Organização Mundial da Saúde (OMS) mantémse como paradigmática, definindo-a como o "estado do mais completo bem-estar físico, mental e social, e não apenas a ausência de doença" (OMS, 1948).

Contudo, a amplitude dessa formulação suscitou, desde seus primórdios, críticas de natureza teórico-técnica e política. Nesse contexto histórico, fazse necessário nomear a crise estrutural da sociedade moderna no século XX (BIRMAN, 2006). Mais especificamente, indicar o cenário que a criação da OMS e de seu conceito de saúde objetivaram constituir como resposta: a devastação e genocídio das guerras mundiais, bem como suas implicações a posteriori. Com efeito, o conceito de saúde da OMS desvela o projeto ético-político de operar uma transformação dos traumatismos infligidos no tecido social em seu oposto. Isto é, substituindo o absoluto mal-estar (produzido pela desumanização radical da guerra), pelo estado ideal de completo bem-estar biopsicossocial.

Residiriam, nessa abordagem do problema, as supostas inconsistências de tal concepção de saúde. Em outras palavras, a resposta governamental e institucional da sociedade em relação à sua própria crise se deu por meio de uma inversão do problema em seu contrário, como dito, do mal-estar absoluto no completo bem-estar. Precisamente, tais estratégias sintomáticas frente à condição humana de desamparo e à necessidade do laço social, já no período entre as duas guerras mundiais, foram explicitadas por Freud em sua crítica da modernidade (FREUD, 1930[2006]).

O campo de forças em jogo, entre saber e poder, no qual a saúde foi inscrita, se estabeleceu segundo Foucault (1978-79[2004]), na modernidade sob a lógica da biopolítica. Esta se instalou no espaço social conforme a medicalização estratégica deste, isto é, conforme a palavra de ordem da qualidade de vida. Objetivou-se, por esta via, a consolidação dos interesses do Estado, visto que a saúde da população seria a condição de possibilidade para produção de riquezas (FOUCAULT, 1978-79[2008]).

Deste modo, a conjugação entre os campos do saber e do poder enunciou uma série de jogos de verdade em favor da legitimação de seus dispositivos. Constitui, 
assim, uma política fundada no manejo insistente e infinito das fontes de vida com o objetivo de produzir riqueza material e regular os laços sociais. Nesse contexto, se desenvolve a produção de discursividades implicadas gestão das subjetividades (FOUCAULT, 1978-79[2008]; BIRMAN, 2009).

Entretanto, é preciso reconhecer que a via entreaberta pelo conceito de saúde da OMS possibilitou que as discussóes acerca dos determinantes históricos, culturais, filosóficos, políticos e econômicos da saúde ganhassem força e visibilidade (SCLIAR, 2007). Sendo assim, a referida crise estrutural viabilizou o remanejamento epistemológico da saúde e a interdisciplinaridade inseriu-se de forma enfática e indissociável (BIRMAN, 2005). Resultou disso um campo de tensões fundado na interdisciplinaridade e intersetorialidade, conforme a crítica sistemática do referencial biomédico e de seus dispositivos sanitários (BIRMAN, 2005). Justo esse campo de tensōes, em suas dimensões plurais de conflito, foi condição de possibilidade para o surgimento do Sistema Único de Saúde - SUS (PAIM, 2012) e da Saúde Coletiva (BIRMAN, 2005).

A introdução das ciências humanas neste debate, portanto, foi essencial para seu redimensionamento. Este olhar crítico voltado para diferentes interfaces da experiência humana reporta-nos à retomada do humanismo como um horizonte ético-político. Nesse sentido, insurgem e convergem as atuais propostas de humanização da saúde (DESLANDES; MITRE, 2009; GOULART; CHIARI, 2010; PASCHE; PASSOS; HENNINGTON, 2011).

A Política Nacional de Humanização (PNH) destinada ao SUS em sua fundação foi constituída pelos seguintes princípios (1) valorização da dimensão subjetiva e social nas práticas de atenção e gestão em saúde; (2) trabalho em equipe multiprofissional; (3) construção de redes cooperativas; (4) construção de autonomia e protagonismo (5) corresponsabilidade nos processos de atenção e gestão; e por fim, (6) democratização das relações de trabalho e valorização dos profissionais de saúde (BRASIL, 2004).

A partir das contribuições de Foucault, Benevides e Passos (2005) articulam noções como governamentabilidade, Estado e política, em torno das problemáticas da atenção e gestão em saúde. Conforme tal elaboração, destacam a inseparabilidade entre os processos de produção de saúde e a produção de subjetividade (BENEVIDES; PASSOS, 2005). Por esta via, afirmam que a humanização compreende os processos de subjetivação situados 
na alteração dos modelos de atenção e gestão, nos quais a saúde é tomada como uma experiência de criação de si, de abertura para novos territórios existenciais (BENEVIDES; PASSOS, 2005).

Portanto, um projeto ético-político direcionado aos processos de trabalho e formação dos profissionais de saúde tornou-se imprescindível (ROSITO; LOTERIO, 2012). A aposta então realizada, em um continuum entre formação permanente em saúde, processos de trabalho e humanização, constitui um cenário no qual a função de cuidado está implicada de forma indissociável. $\mathrm{O}$ cuidado, deste modo, passa a ocupar posição estratégica de conceito organizador das formas de trabalho em saúde (MERHY; FEUERWERKER, 2009; BERNARDES, 2012).

Os processos de subjetivação deste modo seriam permeados, de um lado a outro, pelas práticas humanas de cuidado. Neste ponto, a Teoria Geral do Cuidado, proposta por Figueiredo (2012), é de extrema relevância para o presente estudo. Desde a perspectiva psicanalítica, Figueiredo $(2007 ; 2012)$ propõe uma articulação entre os conceitos-chave de Ferenczi, Winnicott e Bion, autores que enfatizaram em suas obras a função de cuidado como constitutiva do psiquismo e de seus modos funcionamento.

A partir desse percurso teórico, Figueiredo $(2007 ; 2012)$ descreve duas possíveis posições do agente cuidador: presença implicada e presença reservada. Sumariamente, a primeira destas se refere à lógica de intervenções de sustentação e continência das demandas de cuidado. Além disso, abarca o reconhecimento e "espelhamento" da singularidade do indivíduo para o mesmo, viabilizando sua integração enquanto sujeito. Por sua vez, a segunda posição citada reporta-se à possibilidade de espera e aposta no objeto de cuidado (FIGUEIREDO, 2012). O equilíbrio dinâmico entre ambas as posições constituiria uma via possível na produção de saúde através da especificidade dos atos de cuidar. Evidentemente, podem ocorrer falhas em tal equilíbrio, ou ainda, usos não promotores de saúde da função de cuidado (FIGUEIREDO, 2012). Nesta lógica, o cuidado é definido em referência às ocupações e preocupações de cuidados recíprocos, destacando-se sua dimensão ética, que implica habitar e compartilhar (recebendo e transmitindo) o mundo humano (FIGUEIREDO, 2012). Em última instância, as práticas humanas de cuidado seriam, em sua lógica de reciprocidade e alteridade, uma via possível de participação criativa da vida cultural e institucional (FIGUEIREDO, 2012). 
Tendo em vistaas múltiplas relações entrecuidado esaúde, o SUS éconstantemente

desafiado a evitar dissociações no cenário de uma extensa e complexa rede de atenção à saúde. $\mathrm{Na}$ constituição atual dessa rede, desponta um ponto nevrálgico de conflitos estruturais do campo da saúde: entre os níveis de atenção primária e terciária, havendo ainda importantes lacunas no nível secundário. Nesse contexto, o problema da superlotação dos Serviços de Emergência Hospitalar (SEH) passa a ocupar posição de destaque, pois as condiçōes materiais e intersubjetivas da produção do cuidado nesse cenário são postas em xeque (DESLANDES, 2002).

Bittencourt e Hortale (2009) afirmam, a partir de uma revisão sistemática, que o fenômeno da superlotação dos SEH ao redor do mundo indica baixa efetividade organizacional dos sistemas de saúde locais. Com efeito, resulta em diminuição da qualidade assistencial e, consequentemente, aumento dos índices de mortalidade. Trata-se, portanto, de uma questão de grande relevância social (BITTENCOURT; HORTALE, 2009).

O problema da superlotação constante dos SEH do SUS, como dito, coloca em evidência os impasses entre a rede de atenção primária e terciária (BITTENCOURT; HORTALE, 2009). Dificuldades de articulação e efetividade da primeira que desviam o fluxo de atendimentos em direção à segunda, geram o fenômeno da superlotação dos SEH, incapazes de absorver a totalidade de tais demandas (O’DWYER; OLIVEIRA; SETA, 2009). A avaliação dos SEH realizada pelo programa QualiSUS do Ministério da Saúde, aponta que 65\% dos usuários dos SEH poderiam ser atendidos em ambulatórios (O'DWYER; OLIVEIRA; SETA, 2009), situação que se agrava na medida das dificuldades internas dos hospitais em absorver os atendimentos iniciados em seus próprios SEH (O'DWYER; OLIVEIRA; SETA, 2009).

Ainda quanto à avaliação do QualiSUS dos SEH nacionais, destacam-se como problemas principais: ocupação constante dos leitos acima de 100\%; excesso de demandas ou demandas "inadequadas"; limitaçôes em termos de recursos humanos e tecnológicos; ausência de leitos de retaguarda; e planejamento efetivo (O’DWYER; OLIVEIRA; SETA, 2009). São problemáticas que repercutem diretamente nos processos de trabalho nos SEH, principalmente no âmbito das tensões entre resolutividade clínica e práticas fundadas na integralidade e humanização (O'DWYER; OLIVEIRA; SETA, 2009); processos inexoravelmente alinhados com as práticas de cuidado. 


\section{Metodologia}

Objetivando investigar os discursos dos profissionais de saúde de um SEH acerca do cuidado, conforme a justificativa de instrumentalizar discussões acerca dos processos de atenção e gestão nesse contexto, optou-se pelo método genealógico de Foucault. Trata-se de uma abordagem destacada por Nardi et al. (2005) como profícua para atualidade do campo da saúde.

A genealogia de Foucault (1978-79[2008]; 1994[2003]) apoia-se em seu modelo arqueológico (FOUCAULT, 1968 [1997]) e o complementa. A linearidade histórica é assim questionada, visto que o método genealógico aponta sempre no sentido de suas descontinuidades e atravessamentos (THIRY-CHERQUES, 2010). Isto é, como uma forma de problematizar as práticas sociais desde dentro e em sua atualidade (BIRMAN, 2002).

Em linhas gerais, a genealogia investiga as condições de aparecimento e formação dos discursos (DREYFUS, 2010). Deste modo, propõe uma análise dos múltiplos jogos de força e influência que se estabelecem nas relações econômicas, políticas, históricas e culturais (FOUCAULT, 1971[2000]). A própria necessidade de elucidar de maneira abrangente e integrada a formação dos discursos sobre o cuidado, no contexto de um SEH, justifica a escolha metodológica. Neste esforço, tomaremos como arquivos discursivos as entrevistas semiestruturadas realizadas com os participantes, propondo em sua leitura uma discussão interdisciplinar.

O estudo foi aprovado pelo Comitê de Ética em Pesquisa da instituição em que foi realizado e o Termo de Consentimento Livre Esclarecido utilizado com todos os participantes. Em termos de recursos, o financiamento utilizado foi dos próprios pesquisadores e não há conflitos de interesse em sua realização e/ou publicação.

\section{Amostra}

A amostra do estudo é composta de profissionais contratados do referido SEH e selecionada por conveniência. ${ }^{1}$ Os participantes do estudo pertencem aos seguintes núcleos profissionais: Enfermagem (3); Farmácia (1); Fisioterapia (2); Medicina (2); Nutrição (1); Psicologia (1) e Serviço Social (3). Em termos do tempo de conclusão da graduação e de atuação profissional em SEH, não foram coletadas informaçóes precisas de todos os sujeitos, optando-se por não tabular tais dados. Contudo, observou-se uma variação aproximada entre dois e vinte anos de graduação, e em termos da atuação na área, de apenas dois meses a aproximadamente vinte anos. 


\begin{tabular}{c|ccccc}
\hline$N$ & $\begin{array}{c}\text { Sexo } \\
\text { (Feminino) }\end{array}$ & $\begin{array}{c}\text { Cargo* }^{*} \\
\text { (Gestão) }\end{array}$ & $\begin{array}{c}\text { Preceptoria** } \\
\text { (Sim) }\end{array}$ & $\begin{array}{c}\text { Trabalha } \\
\text { em outra } \\
\text { instituição } \\
\text { (Sim) }\end{array}$ & $\begin{array}{c}\text { Pesquisador } \\
\text { (Sim) }\end{array}$ \\
\hline $\mathbf{1 3}$ & $61,5 \%$ & $23 \%$ & $69 \%$ & $38,5 \%$ & $15,4 \%$ \\
\hline
\end{tabular}

* Cargos: gestão ou assistencial ** Experiência prévia e/ou atividade atual

\section{Cuidado no SEH: arquivos do mal-estar}

Desde o início, mas agora com maior objetividade, nos ocupamos de desvelar os enlaces e rupturas nos processos de cuidado e saúde-doença. Nesse sentido, os arquivos das entrevistas, em sua totalidade, convocam-nos em desafio. Em outras palavras: todos os sujeitos, em resposta à primeira questão da entrevista, ${ }^{2}$ recorreram ao significante desafio. Qual seria então, esse desafio?

Se existe um desafio e se desconhecemos seu estatuto ou não conseguimos nos situar em sua complexidade, tal desafio pode tornar-se um jogo de verdade paralisante caso assuma o status e a função de resistência à mudança. Para não incorrermos nessa falha crítica, desde já faz-se necessário visualizar melhor o cenário e as regras do jogo.

Dentre as problemáticas enunciadas pelos profissionais em relação aos processos de cuidado, destacamos as seguintes categorias analíticas: (a) capacidade das instalaçôes; (b) rede de atenção à saúde; (c) formação; e (d) recursos. A despeito dessa organização didática, foram observados na fala dos participantes o reconhecimento de múltiplas relações entre tais categorias, seus possíveis condicionantes e efeitos, e ainda, derivações e transformações no tempo-espaço.

No que se refere à capacidade das instalaçôes, a condição de superlotação foi apontada como problemática central pela totalidade dos participantes. Nesse sentido, o volume e a diversidade de demandas, indicados como resultantes da superlotação, foram diretamente associados ao dito desafio. Os seguintes aspectos e processos foram recorrentemente relacionados à superlotação: demanda excessiva e/ou inadequada; escassez de tempo; diminuição da qualidade da assistência; espaço físico insuficiente e/ou inadequado; dificuldades de identificação de demandas; dificuldades de integração entre diferentes profissionais e equipes; 
ausência de privacidade; fragmentação e/ou impossibilidade na realização das açōes de cuidado; sofrimento e desamparo. Vejamos algumas falas sobre o tema:

Nós estamos há muitos anos numa prática de superlotação [...] é humanamente impossível de atender a todos, dar conta. (P5) ${ }^{3}$

Nesse contexto de empilhamento de pacientes, porque é isso que parece ser, o hospital não consegue agir diferente. Isso acaba limitando bastante [...] Essa é uma questão de gestão, mais do que de gestão, de política, talvez. (P8)

Em termos da rede de atenção à saúde, esta foi descrita como uma rede que falha. Por sua vez, tal falha foi recorrentemente conjugada à superlotação, sendo inclusive muitas vezes considerada sua causa principal. Nesse sentindo, tais falhas foram localizadas nos níveis primário e secundário de atenção à saúde. A especificidade destas falhas, em última instância, consistiria em desvios no fluxo dos pacientes. Contudo, somente três dos participantes reconheceram ou situaram o próprio SEH como parte integrante da rede em pauta. Enfim, a respeito desta categoria, foram relacionados os seguintes aspectos e processos: incapacidade dos níveis de atenção primária e secundária de darem conta das demandas que lhe são pertinentes; descontinuidade das linhas de cuidado; políticas não efetivas; déficits estruturais dos serviços de saúde. Acompanhemos as citações abaixo:

Como é que o SUS está organizado? Qual é a porta de entrada...? Não é a emergência a porta de entrada, mas a atenção primária. (P4)

Não é aqui que essas pessoas deveriam estar consultando, mas por outro lado, se sabe da dificuldade que o usuário tem em relação a isso [...] Então nós acabamos criando uma outra categoria de pacientes para desenvolver o cuidado, são aqueles que dizem 'eu sou da emergência' [...] Sabem inclusive, o dia do melhor médico ou o plantão da enfermeira fulana. (P11)

Em relação a categoria analítica denominada formação, a graduação foi colocada no centro da discussão, embora a formação continuada tenha sido citada de maneira difusa. Sete participantes da pesquisa discorreram sobre o tema da formação, em geral descrevendo-a como: distante dos cenários de práticas; incapaz de dar conta da demanda cotidiana e insuficiente no sentido de proporcionar uma visão interdisciplinar e/ou mais humanizada. Entretanto, apenas um participante relacionou a questão da formação com o fato de que o SEH faz parte de um hospital-escola. Este sujeito foi também o único que situou a residência multiprofissional como processo formativo, mesmo que esta tenha sido destacada pela maioria dos participantes como principal dispositivo de cuidado e de qualificação do SEH (ver adiante). Observemos quanto a isso: 
Existe uma demanda mais ampla do que só a questão clínica propriamente dita né [...]

Questôes de recursos materiais ou de o quanto choca a própria emergência... Diversas situaçôes de fragilidades, pacientes terminais e a disponibilidade para escutar esses pacientes [...] Isso mobiliza muito! Como é que é tu lida com isso? [...] Em termos de formação eu não tive preparo algum para esse tipo de coisa. (P6)

Finalmente, a questão dos recursos associa-se a diversos aspectos pertinentes das demais categorias; destacaram-se porém questōes acerca das condições e processos de trabalho. Nesse sentido, foi maciçamente descrita a situação de falta de recursos. Com efeito, foram enfatizados como faltantes: recursos materiais (de infraestrutura, "hotelaria" e em alguns casos, tecnológicos); humanos (contingente insuficiente de profissionais); de contrarreferência (rede de serviços e/ou unidades de saúde insuficiente e/ou inexistente); e psíquicos (contingencial na relação com os pacientes atendidos; na elaboração das próprias experiências emocionais; no manejo de conflitos com outros profissionais; e por fim, em relação aos processos identificatórios e dilemas éticos com pacientes). Segue um recorte, a título de síntese:

Fazer gestão em saúde é fazer gestão de recursos finitos e escassos [...] Em nenhuma das minhas outras experiências em outros paises, se tem a intensidade, a dramaticidade dos conflitos e problemas que temos aqui nesse serviço [...] O grau de sofrimento, muitas vezes, não tem a intensidade que tem nesse sistema aqui, entende? Se olharmos para esse processo como um processo de trabalho que precisa ser gerido, é um negócio impressionante. (P12).

Destacaram-se no testemunho dos profissionais sobre seus processos de trabalho e subjetivação a presença de séries de opostos na maioria dos relatos, por exemplo, satisfação e frustração; integração e fragmentação, disponibilidade e resistências. Nesse campo de polarizações, a palavra de ordem de dar conta evidenciou seu enlace com as experiências de "sofrimento", "adoecimento", "estresse”, "automatismo", "conflito", “dissociação" e "cronificação". Deste modo, foi enunciada a existência de um perfil do profissional de emergência e, em menor escala, explicitada uma necessidade de autocuidado. Isto no sentido de tornar possível a sobrevivência dos profissionais em tal contexto, o que fica em evidência na fala "a gente vai buscando alternativas de sobrevivência, para poder sobreviver a nossa demanda diária mesmo" (P5).

Em ressonância com o somatório e complexidade destes elementos, o SEH foi nomeado como "caixinha de surpresas", "desorganização organizada", "confusão", "desordem", "guerrilha” e "caos". Diante destas imagens transbordantes de 
angústia, uma pergunta inevitável: como, neste cenário, se faz possível o exercício de uma função de cuidado (FIGUEIREDO, 2012) minimamente equilibrada?

Objetivando mapear os elementos que essa interrogação suscita, adentremos nos dispositivos de cuidado utilizados pelos profissionais em sua prática. Nesse sentido, o discurso dos participantes alternou-se entre a priorização do uso de tecnologias leves ou duras, e ainda, a integração de ambas (tecnologias leve-duras). Por tecnologias leves, compreende-se o âmbito das interações e subjetividade que viabilizam o acolhimento, os vínculos, a corresponsabilização e a autonomização. Ou seja, corresponde ao trabalho vivo na produção do cuidado (MERHY; FEUERWERKER, 2009). Já as tecnologias duras tratamse dos equipamentos e maquinários que se reportam a um outro momento da produção do cuidado, configurando saberes e fazeres materializados, já acabados (MERHY; FEUERWERKER, 2009).

A ênfase no uso de tecnologias leves reportou-se ao conceito de saúde da OMS, mas apresentou-se desconectada das necessidades de resolução clínica nas situaçôes de urgência. Por seu turno, a ênfase nas tecnologias duras promoveria respostas à clínica do paciente crítico, porém, sem incluir outros elementos de forma consistente. A integração de ambas, quando presente reportou-se invariavelmente a existência e/ou intervençōes da equipe multiprofissional.

Enquanto dispositivos de cuidado foram recorrentemente citados: acolhimento; escuta; intervenções clínicas efetivas; avaliação de demandas; eleição de prioridades; humanização da assistência; e continuidade dos atendimentos em saúde através dos sistemas de referência e contrarreferência. A gestão das equipes e relações interpessoais através da comunicação foi citada por apenas dois participantes como um dispositivo relevante. Não obstante, a grande maioria dos sujeitos referiu-se ao programa de Residência Multiprofissional Integrada como ganho fundamental para o SEH em diferentes níveis. Isto é, em termos de (a) resposta às demandas de atendimento, (b) qualificação dos dispositivos acima citados e (c) a própria constituição de uma equipe multiprofissional.

A inserção da residência multiprofissional neste cenário, de fato e de direito, foi condiçãoo de possibilidade para qualificação do $\mathrm{SEH}$, agenciando transformaçôes em importantes aspectos de seu funcionamento. No entanto, coexiste com tais avanços a manutenção de uma estrutura cronificada, como evidenciam os 
recortes apresentados. Mais do que isso, é possível inferir que tal estrutura possui um potencial altamente cronificante dos modelos a ela subjacentes e/ou opostos.

Dinâmica que se apresenta de modo mais ou menos sutil, no discurso coletivo, sustentando-se conforme uma série de jogos de verdade que examinaremos a seguir. De imediato, direcionemos nossa atenção para uma possível fotografia do estado de coisas o qual tentamos apreender:

Já não posso mais pensar o cuidado de uma maneira atomizada. E um serviço desses, em última instância, representa isso: um cuidado provido em vários níveis, por várias pessoas, em várias dimensões etc. Nós temos uma incapacidade de fazer isso de forma sincrônica [...] Isso porque o processo adquire contradições intrínsecas: espera-se de alguma maneira que o profissional, para que ele consiga psiquicamente sobreviver aqui dentro, que ele não faça vínculo. Mas é uma contradição, porque o cuidado não pode ser feito sem vínculo, sem acolhida. Então admite-se o profissional querendo que ele seja capaz de fazer uma prática acolhedora, uma escuta ativa, com capacidades de continência, cuidado humanizado, vínculo etc. [...] Mas implicitamente se diz, ao mesmo tempo, que para ele sobreviver aqui, a regra é que não se faça vínculo [...] Isso gera uma eterna dessincronia [...] processos de alienação ou a criação de mecanismos de perversão [...] ou ainda, gera heróis e mártires, e aqui também não é o lugar para isso. (P12).

Fala que incide no discurso coletivo, em um só tempo, conectando seus fios e desvelando suas descontinuidades. A referida contradição intrínseca do cuidado, entre o estabelecimento de vínculo e sua ilegitimidade ou mesmo deturpação, abre uma janela no horizonte de nossa discussão.

Se existe desequilíbrio entre as condições de trabalho e as demandas insurgentes, sobreviver passa a significar a execução de tarefas de maneira operacional sem vincular-se do ponto de vista psíquico. Nada há de surpreendente nisso, visto que tal sintomática individual e institucional instala-se comumente na dinâmica de equipes que sentem sua sobrevivência como ameaçada (LEBRUN, 2009). Neste caso, conforme a incidência da vulnerabilidade social, sofrimento e morte no cotidiano, soma-se a percepção de não haver respostas assistenciais globalmente efetivas ou, até mesmo, a inexistência de respostas possíveis.

Evidenciar as descontinuidades nos processos de cuidado, em termos de relações humanas, possibilita-nos situar o mal-estar desta experiência com maior precisão. Isto na medida em que inscrevemos os impasses em pauta na sua especificidade do laço social contemporâneo (LEBRUN, 2009; BIRMAN, 2012). Com efeito, a qualidade do encontro reclama sua emergência ao primeiro plano, pois, como dito, as posiçóes ocupadas pelos sujeitos neste encontro trata- 
se dos determinantes cruciais do processo de cuidar. Por essa via, acreditamos ser possível remanejar a relação entre cuidado e saúde, a constituição da equipe multiprofissional, e ainda, introduzir um tema até aqui recalcado: a comunicação.

\section{Encontros e desencontros}

Diante das condições e múltiplos fatores envolvidos nos processos de cuidado no SEH, do ponto de vista psíquico, é inexorável para o profissional a tarefa de processar intensidades que lhe atingem, vindas de todos os lados, no campo em que se encontra - situação, em última instância, resultante dos desequilíbrios previamente discutidos. Compreendemos agora com maior clareza, a uso da expressão "guerrilha" no contexto de um serviço de saúde e do ato de cuidar.

No front de batalha, se incapaz de "dar conta" desta tarefa impossível, não há outra possibilidade de sobrevivência para o sujeito, senão o uso de vias colaterais para o escoamento ou bloqueio de tais intensidades. Surgem daí, automatismos, dissociações e perversões. Frente ao “caos" instaurado nessa cena do cuidado em saúde, a qualidade do encontro e o potencial simbólico das práticas de cuidado perdem sua vivacidade. Nesse sentido emergem as falas:

De alguma forma é preciso manter os processos de cuidado vivos, com o perdão da redundância. (P12).

Estou dando alguns exemplos da minha prática, mas na verdade, eu não sei explicar direito o que é esse cuidado. (P13).

Tu levantar a palavra cuidado numa emergência é simbólico [...] Por que as pessoas pouco fazem isso, isso de refletir sobre o que é cuidado [...] Fiquei pensando o quanto a gente não fala em cuidado. Nós falamos muito em tratamento, procedimento, que a gente ou o médico vai fazer, mas não falamos o que é que se vai fazer para cuidar desse paciente. (P7).

Podemos apreender destas falas, uma virtual impossibilidade de se conceituar ou realizar o cuidado, assim como a incidência de uma possível desconexão deste com as intervençõos técnicas dos profissionais. Bem entendido, tais virtualidades referem-se aos desafios das práticas de cuidado e a dinâmica do SEH em questão. Deste modo, o dito efeito simbólico seria justo a possibilidade de ressignificação da noção de cuidado e por esta via, a restituição de sua potencialidade na produção de saúde.

$\mathrm{Na}$ medida em que a saúde é multifacetada e indissociável das açōes de cuidado (FIGUEIREDO, 2012), a existência da equipe multiprofissional foi 
referenciada pelos participantes da pesquisa como principal dispositivo de tal processo. Portanto, seria o trabalho integrado desses diferentes profissionais, ou seja, a interdisciplinaridade, o seu fundamento essencial. Entretanto, a interdisciplinaridade não é enunciada no discurso dos participantes enquanto lógica de trabalho em equipe, sendo o termo multiprofissional empregado maciçamente nesse sentido. No discurso coletivo, portanto, coincidiria e se confundiria a composição da equipe com a lógica do processo de trabalho. É preciso assinalar que equipes multiprofissionais podem atuar de diferentes formas, quais sejam: multidisciplinar, interdisciplinar e transdisciplinar (MINAYO, 2010).

O programa de residência em questão denomina-se multiprofissional integrado em referência justo ao modelo interdisciplinar. Não obstante, a equipe multiprofissional que atua de forma "não integrada" opera de modo multidisciplinar. Isto é, quando há justaposição das diferentes disciplinas em relação ao mesmo objeto, mas sem diálogo e complementaridade efetivos (MINAYO, 2010).

A integração da equipe multiprofissional pressupõe um encontro cuja qualidade, sem dúvidas, dependerá de como se tecem as redes de relações de seus membros. Os papéis exercidos e as trocas estabelecidas, sempre reguladas pela linguagem (LEBRUN, 2009), colocam em evidência de forma inescapável, os processos de comunicação.

Surpreendeu-nos, contudo, que dentre as problemáticas emergentes no discurso dos profissionais entrevistados, a comunicação tenha sido referida como tal, por apenas dois sujeitos. Além disso, os processos decisórios como espaço crucial da integração entre profissionais e equipes, foram citados por somente um participante. Com isso, é possível pensar que se há uma "rede que falha", trata-se de uma rede de linguagem.

Se a palavra não circula é o universo simbólico que se desfaz e, com efeito, a realidade se desordena. Torna-se, deste modo, um "caos" e uma "confusão". Ao mesmo tempo, tais falas apontam um esforço de inscrição no registro simbólico. Movimento conjugado à condição de superlotação dos SEH, conforme os "pacientes que estão no lugar errado" (P11) buscam nesse local, justo uma forma de inscrição de seu sofrimento (DESLANDES, 2002; SÁ; CARRETEIRO; FERNANDES, 2008) - seja qual for a forma de sofrimento colocada em cena.

O SEH de "porta de entrada para o SUS" (P4) desloca-se para posição de porta 
de acesso e inscrição dos sujeitos em um sistema simbólico, fundado nos processos de cuidado. Na relação dos usuários com a equipe de saúde e a instituição que representam, inaugura-se um campo transferencial. Nada há de novo nisso, mas a forma maciça com que essa demanda é endereçada aos profissionais de saúde, através da condição de superlotação, evidencia o remanejamento biopolítico do espaço social e a carência de outras formas de vinculação institucional.

Frente ao desamparo imposto por uma condição clínica ou pela vulnerabilidade social, mais comumente por ambos, o sujeito busca a inscrição que lhe for possível. "Eles nem escolhem outros lugares, porque sabem que aqui vão achar as pessoas acolhem, que cuidam", diz um participante (P2). Observamos com isso, o duplo efeito simbólico do resgate dos processos de cuidado no campo da saúde: de um lado, a emergência de inscrição dos usuários no laço social e, de outro, o reposicionamento dos profissionais de saúde nesta trama.

Precisamente nesse contexto, a equipe multiprofissional foi referida como sendo o principal dispositivo de cuidado. De que forma, então, a equipe responde a essa complexa demanda? Como se articulam suas posições de implicação e reserva nas ações de cuidado? Qual a função da comunicação nesse emaranhado de fatores?

\section{Jogando com a verdade do cuidado multiprofissional}

Uma noção ampliada de saúde, de fato e direito, é reconhecida como paradigma pelos sujeitos entrevistados. Além disso, se a demanda de trabalho é intensa, múltipla e os recursos são limitados, a existência de uma equipe multiprofissional se justifica como alternativa. Indagamos sobre este aspecto: seria esta uma alternativa de sobrevivência ou de redimensionamento dos processos de cuidado?

Posições convergentes e conflitantes. Para que ocorra um redimensionamento do cuidado é preciso, antes de tudo, manter seus agentes e processos vivos do ponto de vista subjetivo. E conflitante na medida em que a dinâmica do cuidado em saúde implica modalidades de inscrição dos sujeitos no laço social que não se reduzem a sua sobrevivência. Nem dos usuários do SUS, tampouco dos trabalhadores.

Com efeito, as intervenções dos profissionais podem e devem ser situadas no registro ético-político (MERHY, 2013), promovendo assim sua ressignificação no espaço social ao reconhecer seu papel na vida coletiva e na produção de subjetividade. 
Nesse sentido, os programas de residência multiprofissional integrada constituem estratégia de gestão do SUS que objetiva a formação de profissionais assim implicados (FERREIRA; OLSCHOWSKI, 2010). No próprio SEH estudado, a configuração atual da equipe multiprofissional decorre da inserção da residência multiprofissional e de um processo de acreditação hospitalar.

Considerando-se o conceito de saúde da OMS, passando pela literatura das áreas da saúde e humanas, e finalmente, situando-nos nos princípios e diretrizes do SUS, a importância das equipes multiprofissionais e das práticas interdisciplinares tornou-se ponto pacífico - discurso que passou a ser repetido como verdade no campo da saúde.

De fato, não há dúvidas a respeito da relevância da interdisciplinaridade. Porém, observamos em nossa investigação um deslocamento na linguagem usual, do conceito de interdisciplinar para o de multiprofissional. Deste modo, o termo "multiprofissional integrado" e o conceito de "interdisciplinaridade" foram citados apenas duas vezes cada, conforme a priorização do termo "multiprofissional".

A equipe multiprofissional enquanto dispositivo assistencial torna-se, portanto, condição de possibilidade para o surgimento de um discurso da multiprofissionalidade. Discursividade sustentada através do jogo de verdade que pressupõe, na existência da equipe multiprofissional, uma materialização dos princípios do SUS e das políticas de humanização em saúde. Não obstante, o termo "humanização" foi mencionado por quatro participantes, mas apenas uma vez como uma política em saúde.

Nesse jogo, a composição da equipe é o seu fim último, sendo os processos de trabalho deslocados para periferia. Vejamos os seguintes recortes:

Aqui o diferencial para o paciente é existir essa equipe multi. Em muitos outros lugares não existe. (P9)

O cuidado é feito por várias disciplinas, né? (P10).

Uma vez teve a atuação de uma residente junto no box de emergência, aquilo eu realmente achei foi equipe multi. Ela e a enfermeira me ajudando a convencer a paciente $[\ldots](\mathrm{P} 2)$.

O termo "multiprofissional integrado", que em si mesmo já não se equivale ao conceito de interdisciplinaridade, é utilizado de forma coloquial em alusão ao mesmo. Conforme a exclusão do significante integrado, opera-se um 
legítimo recalcamento da interdisciplinaridade. Com isso, o capital simbólico da atenção integral à saúde, o qual se inscreve no registro interdisciplinar, não é mais transmitido efetivamente quando se dissemina de forma travestida no âmbito da linguagem.

Retorna, através disso tudo, a dita contradição intrínseca do processo de cuidado. A interdisciplinaridade deslocada para o discurso da multiprofissionalidade, converte-se de dispositivo de mudanças em jogo de verdade da biopolítica. Incide, deste modo, no sentido da cronificação do SEH. A seguinte metáfora ilustra esse estado de coisas:

Cada vez que um paciente cruza aquela porta [da emergência], ele dispara um cronômetro simbólico na direção da cronificação. A gente faz isso com eles. $\mathrm{O}$ olhar da perspectiva multiprofissional precisa ser necessariamente um olhar crítico, reflexivo, que nos ajude a romper com essa inércia que parece ser inexorável nos sistemas, modelos e programas de intervenção em saúde. E não é o emergencista médico, sozinho enquanto profissional, que vai dar conta disso... (P12).

Avancemos nesse raciocínio: se pela via da reflexão crítica poderia ocorrer uma ruptura com o atual estado de inércia, é justo nesse ponto que equipe multiprofissional agregaria seu valor. Isto porque uma especialidade profissional é aqui reconhecida, de fato e de direito, como insuficiente para responder a toda complexidade que viemos sublinhando. Destaca-se disso a reflexão crítica como possibilidade de elaboração do problema da cronificação. Pensamento crítico e compartilhado o qual podemos nomear, sem rodeios, como interdisciplinar.

Entretanto, observamos no uso da palavra "multiprofissional" diversos paradoxos e ambivalências; e ainda, a exclusão da comunicação como processo fundamental. Seria precisamente este o desenho de nosso desafio: convocar uma reflexão, interdisciplinar e crítica dos processos assistenciais no SEH.

\section{Alteridade e convergência}

O discurso da multiprofissionalidade em alusão à lógica interdisciplinar revelou-se como uma fotografia imprecisa do cuidado no SEH. Imprecisa, pois subentende um funcionamento, enquanto de fato, opera a manutenção do status quo. Lembremos que justo o conceito de jogos de linguagem de Wittgenstein (1961[1999]) é a noção da qual Foucault (1971[2003]) parte na concepção dos jogos de verdade, os quais ocupam posição estratégica na consolidação do discurso biopolítico. 
Em outras palavras, a equipe apresenta dificuldades de atuar de forma integrada, pois os profissionais permanecem centrados nos núcleos profissionais, evidenciando dificuldades de refletir criticamente enquanto equipe acerca dos processos de cuidado. Isto porque há uma falha no campo simbólico da linguagem, tanto no que se refere à definição de categorias teóricas fundamentais, quanto em termos da comunicação entre os profissionais.

Dito isto, podemos situar com maior precisão o mal-estar dos profissionais ao declararem sua impossibilidade de "dar conta": suas intervenções clínicas por mais efetivas que sejam, isoladamente não dão conta de modificar o estado de cronificação observado no SEH. Não havendo o devido reconhecimento dos diferentes papéis dos membros da equipe e sem internalização da lógica interdisciplinar, não se estabelecerá comunicação efetiva, tampouco convergência das ações e linhas de cuidado.

Qual seria então, a posição ocupada por tais profissionais em termos da função de cuidado? De fato e de direito, tais profissionais encontram-se implicados na resposta à demanda clínica concreta. Contudo, nas dimensões do trabalho em equipe, processos decisórios, gestão de fluxograma etc. ocorre uma não implicação. Extensão da mesma dinâmica de "contradição intrínseca" do cuidado, anteriormente descrita. Ou seja, evita-se o vínculo ou outras formas implicação, em um só tempo, em razão das necessidades de "sobrevivência" e por resistências à mudança. Em última instância, tal dinâmica resulta numa relação de externalidade dos sujeitos com a sua posição no laço social, bem entendido, marca da vida coletiva na contemporaneidade (LEBRUN, 2009).

Observamos nestas modalidades de não implicação subjetiva, falhas estruturais no âmbito da linguagem. Seja através de jogos de verdade, seja em decorrência de uma confusão de línguas. Isto é, conforme a especificidade de formação, cada profissional constitui-se como "estrangeiro" para os demais. A equipe multiprofissional, deste modo, é um potencial operador da alteridade. Além disso, a metáfora do estrangeiro sublinha a delimitação do território de intervenção de cada profissional; e ainda, evidencia a grande complexidade da comunicação entre os "falantes de diferentes idiomas". Se tais fatores não são ordenados e simbolizados através de uma linguagem minimamente transversal, constitui-se uma verdadeira babel. 
Conclui-se de tudo isso que não há possibilidade de convergência no cuidado sem a incidência simbólica da alteridade. Não obstante, se ocorrem falhas no âmbito da linguagem e com isso, surgem formações discursivas sintomáticas, faz-se necessário um remanejamento deste campo. Precisamente nesse sentido, propomos uma definição de interdisciplinaridade enquanto alteridade e convergência. Deste modo, seria agenciada uma experiência de descentramento dos sujeitos e núcleos de formação, configurando um reposicionamento dos profissionais de saúde no laço social. Ou seja, tanto em suas interações com equipes de trabalho e usuários do SUS, quanto no registro ético-político correspondente. Não seria esta, dita em outras palavras, a proposta da PNH (BRASIL, 2004)?

\section{Considerações finais}

A análise dos discursos em torno do cuidado no SEH aponta para as situaçõeslimite em que tal processo se desenvolve: fronteiras entre a vida e a morte, implicação e alienação, limites das condiçōes materiais e subjetivas, etc. Nesse sentido, a própria pesquisa encontra-se em situação análoga. Enfatizamos, assim, a relação inversamente proporcional entre o espaço textual de um artigo e a complexidade do tema abordado, enquanto importante limitação do estudo.

"A metáfora é a de uma simultânea de xadrez", afirmou-nos com precisão um dos participantes (P12). Em consideração a isto, destacamos alguns temas a serem investigados em novas pesquisas. Além disso, observou-se que as transformaçôes no laço social contemporâneo apresentam repercussões e reproduções diretas na cena do cuidado no SEH. Nisto não há surpresa; no entanto, o campo transferencial inaugurado nesse contexto e as respostas dos profissionais a tal demanda convocam-nos ao desafio de compreender de maneira mais consistente o laço social que assim se estabelece.

Não obstante, estudos sobre a apropriação subjetiva de práticas interdisciplinares e comunicação nos SEH também se fazem necessários. Como se organizam e definem os papéis nas equipes multiprofissionais? Existem conceitos transversais que devem ser compartilhados pelos membros de tais equipes? De que forma são transmitidos? Quais seriam os principais déficits na formação dos profissionais de saúde e como podem ser remanejados? Nesse contexto, seria possível introduzirmos a noção de cuidado de si (FOUCAULT; 1981[2010]) como fundamento das práticas de saúde? ${ }^{4}$ 


\section{Referências}

BENEVIDES, R.; PASSOS, E. A humanização como dimensão pública das políticas de saúde. Ciência \& Saúde Coletiva, v. 10, n. 3, p. 561-571, 2005.

BERNARDES, A.G. Potências no campo da saúde: o cuidado como experiência ética, política e estética. Barbarói, v. 36, n. 1, p. 175-190, 2012.

BIRMAN, J. A Physis da Saúde Coletiva. Physis Revista de Saúde Coletiva, v. 15 (supl.), p. 11-16, 2005.

. Arquivos do mal-estar e da resistência. Rio de Janeiro: Civilização Brasileira, 2006.

. Cadernos do mal: agressividade, violência e crueldade. Rio de Janeiro: Record, 2009.

. Jogando com a verdade. Uma leitura de Foucault. Physis Revista de Saúde Coletiva, vol.12, n.25, p. 301-324, 2002.

- Mal-estar na atualidade: a psicanálise e as novas formas de subjetivação. Rio de Janeiro: Civilização Brasileira, 2007.

. Sujeito na contemporaneidade: espaço, dor e desalento na atualidade. Rio de Janeiro: Civilização Brasileira, 2012.

BITTENCOURT, R.J.; HORTALE, V.A. Intervenções para solucionar a superlotação nos serviços de emergência hospitalar: uma revisão sistemática. Cadernos de Saúde Pública, v. 25, n. 7, p. 1439-1454, 2009.

BRASIL. Ministério da Educação. Resolução da Comissão Nacional de Residência Multiprofissional em Saúde. Brasília: MEC, 2012.

. Ministério da Saúde. HumanizaSUS: Política Nacional de Humanização. Brasília: MS, 2004.

DESLANDES, S.F. Frágeis deuses: profissionais da emergência entre os danos da violência e a recriação da vida. Rio de Janeiro: Fiocruz, 2002.

DESLANDES, S.F.; MITRE, R.M. Processo comunicativo e humanização em saúde. Interface: Comunicação, Saúde e Educação, v. 13, n. 1, p. 641-649, 2009.

DREYFUS, H. Michel Foucault: uma trajetória filosófica: para além do estruturalismo e da hermenêutica. Rio de Janeiro: Forense Universitária, 2010.

FERREIRA, S.R.; OLSCHOWSKI, A. Residência: uma modalidade de ensino. In: FAJARDO, A.; ROCHA, M.C.; PASINI, V.L. Residência em Saúde: fazeres \& saberes na formação em saúde. Porto Alegre: Grupo Hospitalar Conceição, 2010.

FIGUEIREDO, L.C. A metapsicologia do cuidado. Psychê, v. 11, n. 21, p. 13-30, 2007.

. Cuidado e saúde: uma visão integrada. Alter Revista de Estudos Psicanaliticos, v. 29, n. 2, p. 11-29, 2012.

FOUCAULT, M. A hermenêutica do sujeito: curso dado no Collège de France (1981-1982). São Paulo: Martins Fontes, 2010. 

. Arqueologia do saber (1968). Rio de Janeiro: Forense Universitária, 1997.

. Ditos e escritos, v. II Arqueologia das ciências e história dos sistemas de pensamento (1971). Rio de Janeiro: Forense Universitária, 2000.

. Ditos e escritos, v. IV Estratégia poder-saber (1971). Forense Universitária, 2003.

. O nascimento da biopolitica: curso dado no Collège de France (1978-79). São Paulo: Martins Fontes, 2008.

FREUD, S. O mal-estar da civilização (1930). In STACHEY, J. O futuro de uma ilusão, o mal-estar da civilização e outros trabalhos. Rio de Janeiro: Imago, 2006, v.13 (Edição Standard Brasileira das Obras Psicológicas Completas de Sigmund Freud).

GOULART, B.; CHIARI, B. Humanização das práticas de saúde: contribuições para uma reflexão. Ciência \& Saúde Coletiva, v. 15, n. 1, p. 255-268, 2010.

LEBRUN, J-P. Clínica da instituição: o que a psicanálise contribui para vida coletiva. Porto Alegre: CMC, 2009.

MERHY, E.E.; FEUERWERKER, L.M. Novo olhar sobre as tecnologias de saúde: uma necessidade contemporânea. In: MANDARINO, A.C.S.; GOMBERG, E. (Orgs.). Leituras de novas tecnologias e saúde. Salvador: EdUFBa, 2009.

MERHY, E.E. Residências Integradas em Saúde. Aula Magna da Residência Integrada em Saúde. Porto Alegre: Grupo Hospitalar Conceição, 2013.

MINAYO, M.C. Disciplinaridade, interdisciplinaridade e complexidade. Emancipação, v. 10, n. 1, p. 435-442, 2010.

NARDI, H.C. et al. Fragmentos de uma genealogia do trabalho em saúde: a genealogia como ferramenta de pesquisa. Cadernos de Saúde Pública, v. 21, n. 4, p. 1045-1054, 2005.

O’DWYER, G.O.; OLIVEIRA, S.P.; SETA, M.H. Avaliação dos serviços hospitalares de emergência do programa QualiSUS. Ciência \& Saúde Coletiva, v. 14, n. 5, p. 1881-1890, 2009. ORGANIZAÇÃO MUNDIAL DA SAÚDE. Carta Magna. Genebra: OMS, 1948.

PAIM, J.P. O que é o SUS. Rio de Janeiro: Fiocruz, 2012.

PASCHE, D.; PASSOS, E.; HENNINGTON, E. Cinco anos da Política Nacional de Humanização: trajetórias de uma política pública. Ciência \& Saúde Coletiva, v. 16, n. 11, p. 4541-4548, 2011.

ROSITO, M.M.B.; LOTERIO, M.G. Formação do profissional em saúde: uma recusa ao esvaziamento de essência do cuidado humano. Educação e Realidade, v. 37, n. 1, p. 125-142, 2012.

SÁ, C.M.; CARRETEIRO, T.C.; FERNANDES, M.I. A. Limites do cuidado: representações e processos inconscientes sobre a população na porta de entrada de um hospital de emergência. Cadernos de Saúde Pública, v. 26, n. 6, p. 1334-1346, 2008. 
SCLIAR, M. História do conceito de saúde. Physis Revista de Saúde Coletiva, v. 17, n. 1, p. 29-41, 2007.

THIRY-CHERQUES, H. À moda de Foucault: um exame das estratégias arqueológica e genealógica de investigação. Lua Nova, n. 81, p. 215-248, 2010.

WITTGENSTEIN, L. Investigaçôes filosóficas. São Paulo: Nova Cultural, 1999.

\section{Notas}

${ }^{1}$ Inicialmente, o estudo possuía a pretensão de randomizado, mas em virtude de dificuldades administrativas de acesso ao quadro geral de trabalhadores e de indisponibilidades de agenda, optou-se por rever a forma de seleção da amostra.

2 "Como é para você trabalhar no SEH?"

${ }^{3}$ P: Participante

${ }^{4}$ S.M. Silva participou da concepção do projeto, análise dos dados, redação do artigo e aprovação da versão final a ser publicada. M.Z. Ramos participou da concepção do projeto, análise dos dados, revisão crítica e aprovação da versão final a ser publicada. 


\section{Health professionals of a hospital emergency service: discourses about care}

This study aims to investigate the discourses about care and its implications for health services of health professionals from a hospital emergency service. The research is qualitative and the discursive files were collected through semi-structured interviews with these professionals. It is used, in the analysis of such files, Foucault's genealogical method, providing an interdisciplinary discussion and establishing a critical reading in response to the research question. In this sense, it is emphasized the ethical and political implications across the current reality of the health system. Along the argument, it is discussed the concept of health and their relationships with the notion of care, placing, in this context, the speeches of the participants about their everyday experience and questioning the games of truths actually observed. It follows from the analysis performed by the study, the emergence of re-discuss and redeploy, the scenario at hand, communication processes and the concept of inter-disciplinarity. It is proposed, therefore, the revitalization of care practices and the effective humanization of the processes involved.

> Key words: health care; hospital emergency service; interdisciplinarity; communication. 